\title{
A PROTOTYPE FOR SPRAYING PESTICIDE USING VISION TECHNIQUE
}

\author{
Mohamed F.A. Khairy ${ }^{1}$, Ashraf K. Zaalouk ${ }^{2}$, Ahmad S. Rasmi ${ }^{3}$ and Yasser K. Othman ${ }^{4}$, \\ ${ }^{1}$ Prof. Emeritus of Ag. Power \& Machinery., Fac. of Ag. Eng., Al-Azhar U., Egypt. \\ ${ }^{2}$ Prof and Deputy Dean of Fac. of Ag. Eng., Al-Azhar U., Egypt. \\ ${ }^{3}$ Assist. Prof. Emeritus. of Ag. Machinery., Fac. of Ag. Eng., Al-Azhar U., Egypt. \\ ${ }^{4}$ Assist. Lect., Ag. Mach. \& Power Eng. Dept., Fac. of Ag. Eng., Al-Azhar U., Egypt., \\ Yasser.kamal@azhar.edu.eg
}

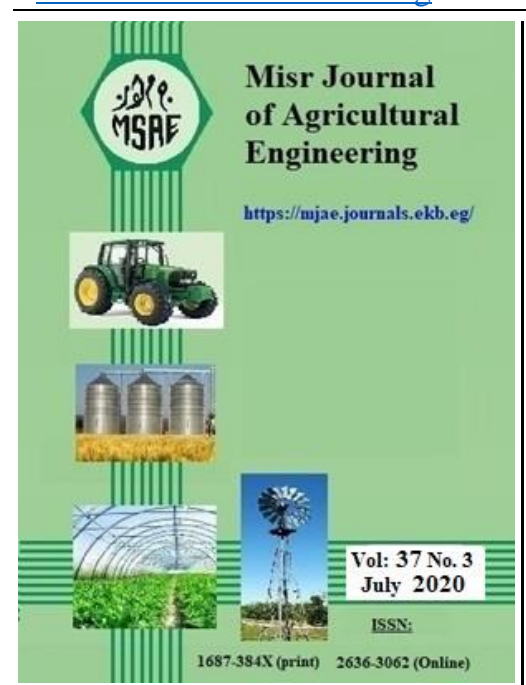

C Misr J. Ag. Eng. (MJAE)
Keywords: Vision technique, spraying pesticide, pesticide saving, pesticide pollution reduction, images analysis.

\begin{abstract}
The spraying of horticultural crops is done by spray all unit area, including the inter-tree distance, which leads to large losses of applied pesticide, pollution of soil and groundwater. To overcome these problems a prototype of a spray machine was manufactured using principle of vision technique. The first stage of experiments was carried out in the laboratory of the faculty of Agric. Eng., Al-Azhar Univ., Nasr city, Cairo to study the analysis of images and response time of electronic components and discharge of different nozzles. The images analysis was carried out to find the color values (RGB) of the trees (orange) used in the experiments and adapted them in the history of program. The tree images were taken each an hour at distances of 1,3 , and $5 \mathrm{~m}$ at a daytime from 5.00 tol0.00 am and from 3.00 to $6.00 \mathrm{pm}$. The second stage of experiments was carried out to calculate the percentage of savings and economical. Four forward speeds $(0.27,0.55,0.85$ and 1.12 $\mathrm{m} / \mathrm{s}$ ), four types of nozzles and four spray pressures (250, 300, 350 and $400 \mathrm{kPa}$ ) were studied. The camera was installed at distances of $0.74,1.5,2.33$ and $3.07 \mathrm{~m}$ to overcome the response time of electronic components at forward speeds of $0.27,0.55,0.85$ and $1.12 \mathrm{~m} / \mathrm{s}$, respect. The maximum percentage amount of saving spray liquid was $57.57 \%$ at nozzle type $\mathrm{N4}$, spray pressure of $400 \mathrm{kPa}$ and spray forward speed of $0.27 \mathrm{~m} / \mathrm{s}$ by using vision technique than without.
\end{abstract}

\section{INTRODUCTION}

$\mathrm{P}$ esticides are substances used to control plant life for the purposes of increasing and improving agricultural production, protecting public health from pest-borne disease and discomfort, reducing property damage caused by pests, and improving the aesthetic quality of outdoor or indoor surroundings (Oerke, 2006). According to FAO statistic 2016 Egypt consumed about 8043.71 metric ton of pesticides, which represent $0.25 \%$ of the global consumption (equal to 52 billion dollars) (FAO, 2016). The spraying of horticultural crops is done by traditional 
spraying machines which operate continuously throughout the unit area, including the inter-tree distance, which leads to: A large losses of pesticide used, increasing pollution of the soil and drift of liquid spray away from the injured field. Vision technique is one of the fields of computer science, which aims to build intelligent applications capable of understanding the content of images as understood by humans. Where data can take several forms such as successive images (video), which is viewed from several cameras, data of several dimensions taken from a camera. Brosnan and Sun, (2004) reported that the machine vision system color capability requires four data elements, one each at the red $(\mathrm{R})$, green $(\mathrm{G})$, and blue (B) wavelengths with the corresponding luminous level $(\mathrm{L})$. The production of color on a monitor is achieved by energizing the three components in a manner to produce the resultant color. In color image processing algorithm, the $\mathrm{L}$ has an important role as it helps deciding the edge of different segments. In indoor applications, such as automated inspection systems the use of artificial light with constant intensity can solve the problem. Padmavathi and Thangadurai (2016) examined and analyzed the Grayscale and RGB images using image techniques such as preprocessing, segmentation, clustering for detecting leaves diseases. RGB image has given better clarity and noise free image, which is suitable for infected leaf detection than Grayscale image. Merritt et al., (1994) mentioned that the on/off control is another approach to selective spraying in which it is critical that the nozzles are activated when they are in close proximity to weeds locations. One method to implement on/off control is to place the sensing results in a queue, thereby providing a delay based on distance between sensors and nozzles; and vehicle speed. Brown et al. (2008) developed a commercial target-sensing spray system in order to quantify the resulting reduction in insecticide in surface water runoff from the orchard. The target-sensing sprayer produced a $40 \%$ reduction in the spray application rate and achieved a $41 \%$ reduction in ground deposition compared with the conventional air-blast sprayer. Pesticide concentration in surface water runoff was reduced by $44 \%$ with the target-sensing sprayer versus the conventional application. Ismail, et al. (2015) indicated that increase both spray pressure and nozzle tip size tended to increase the average of flow rate.

The objective of this research was to study the utilization of vision technique in pesticide control which could be achieved by:

- Manufacturing a prototype of the horticultural crops spraying machine and installing an automatic vision unit on it.

- Perform image processing to obtain the optimal color values for the plant used in spraying.

- Study and evaluated the performance of the prototype sprayer.

\section{MATERIALS AND METHODS}

In order to study vision technique, a sweet orange trees (Citrus sinensis) was used in this research. The experimental prototype was developed and constructed at the Faculty of Agricultural Engineering workshop. The main components of the experimental prototype are main frame, transmission system, electronic parts, hydraulic parts and the transmission system, electronic parts and hydraulic parts were installed on the main frame as shown in Figures (1 and 2). The main frame was constructed from $\mathrm{L}$ shape mild steel. The dimensions of frame length, width and height were 93, 52 and $80 \mathrm{~cm}$ respectively. A $300 \mathrm{~cm}$ length of $\mathrm{L}$ shape mild steel was assembled at the left sides on the front of the prototype. There were some holes with diameter of $0.08 \mathrm{~cm}$ at equal 
distances about $10 \mathrm{~cm}$ to install webcam arms. The webcam arm was a par of steel with a length of $35 \mathrm{~cm}$. There was another arm with a length of $50 \mathrm{~cm}$ was used to support the nozzle at the rear of the experimental prototype. The experimental prototype was constructed to work equal at the two sides but according to the experimental condition the measurements were taken at the left side only. The experimental prototype was loaded on four compacted rubber wheels with a diameter of 25 $\mathrm{cm}$, rim diameter of $19 \mathrm{~cm}$ and width of $5 \mathrm{~cm}$. The transmission system was operated by an electric DC motor $(24 \mathrm{v}-60 \mathrm{w})$ to operate the rear wheels by two sprocket gears and chain. The main components of the electronic parts were classified as follows: digital webcam, Raspberry pi board, Arduino board, digital screen, relay module, solenoid valve, and power supply.

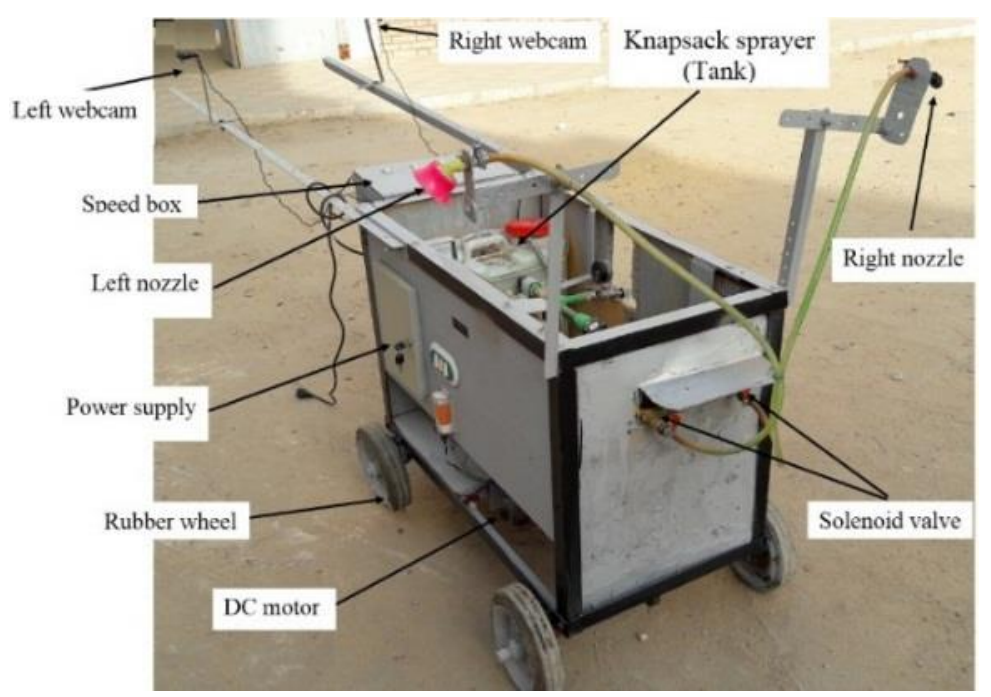

Fig. (1). Vision sprayer prototype

A digital webcam was used to capture the tree image. The raspberry pi 2-model B board was used to process the image from the webcam and transferred the signal to other electronic components in the prototype. Raspberry pi board was used for DBS (digital signal processor) presence which is not available in the Arduino board. The Arduino uno board was used to transfer the signal from the raspberry pi board to the other electronic components in the prototype. A digital screen was used to display the discharge (L/min). and the webcam signal in the form (Cam: NGR or GR) where (NGR): no green signal and (GR): green signal. The relay module consists of two channels $12 \mathrm{v}$. The solenoid valve was used in this study to control the spray action (on or off) automatically according to the signal from raspberry bi board and the electric components. The power supply was used to convert $220 \mathrm{~V}$ AC to $12 \mathrm{~V}$ DC to operate the relay module and solenoid valves. A $5 \mathrm{~V} \mathrm{DC}$ power bank was used to operate the electronic boards. The main components of the hydraulic parts are a knapsack sprayer with diaphragm pump, nozzles and pressure regulator. Four different types of nozzles were used in this research. (N1: one outlet, one hole of $1.92 \mathrm{~mm}$ diameter; N2: two outlets, one hole for each of $1.88 \mathrm{~mm}$ diameter; $\mathrm{N} 3$ : one outlet, four holes of $1.16 \mathrm{~mm}$ diameter; and N4: one outlet, five holes of $1.08 \mathrm{~mm}$ diameter). Each nozzle was calibrated at four pressures of $250,300,350$ and $400 \mathrm{kPa}$ to obtain the nozzle discharge. 

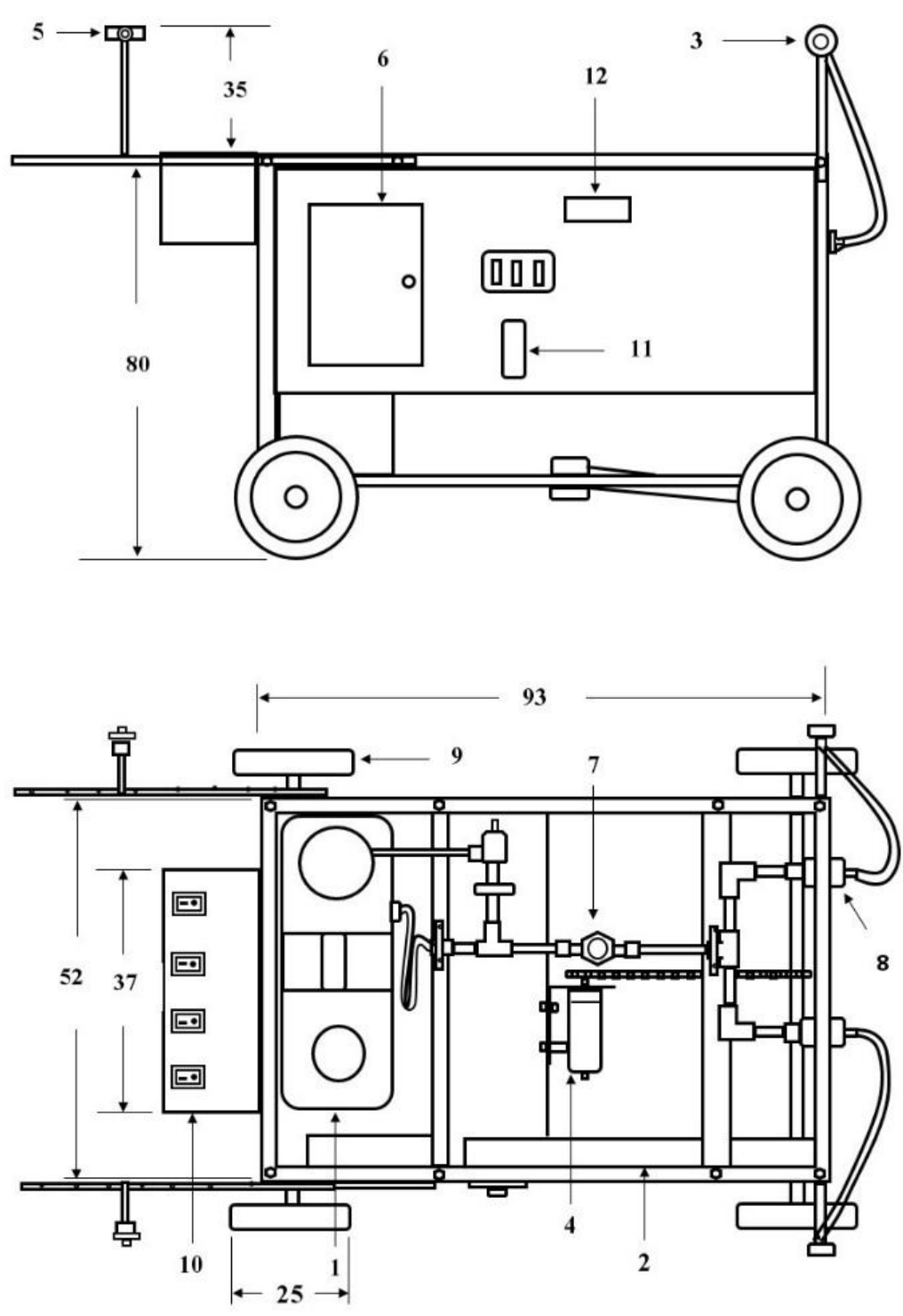

1. Knapsack sprayer

2. Control unit.

3. Nozzle.

4. Dc motor.
5. Webcam.

6 . Power supply.

7. Flow rate sensor.

8. Solenoid valve
9. Wheel.

10. Speed box.

11. Power bank

12. LCD display.

\section{Fig. (2): Schematic diagram for vision sprayer prototype}

The pressure regulator was set manually to control the needed pressure. During operating the system, the signal was transferred from the webcams located at the left side, that faced the plant to the raspberry pi board and from it to another Arduino board. The captured image occurs and converts it to RGB values, which are compared to the RGB values in the raspberry pi program for each (low and high values). If the values are identical or within the boundary, the signal is passed to the relay for operation to start of spray. If the values are different or outside the RGB values, the signal is passed to the relay for no signal to stop of spray. The time consumed between the signal from the webcam and starting or ending a spray process was defined as response time. The experiments were divided into laboratory and field experimental: The laboratory experiments were carried out to study the processing and analysis of images, response time to define the leading distance between webcam and nozzles. The field experiments were carried out to study the amount 
and intensity of spray liquid with and without vision technique technology. The laboratory experiments consist of image analysis and prototype electronic circuit response time. In vision technique, a code required to the raspberry bi board program to identify a certain plant. This code obtained by a several ways regarding to the image of the plant that was taken by a system webcam. The quality of the image depends on system webcam resolution, daylight and the distance between the plant and webcam. Therefore, such experiments have been done to find a code of orange tree, which used in this research, using RGB color system by using ENVI v 5.1 program. A weather sensor unit was used to measure the light intensity in the location of target trees every hour from 5 am to $6 \mathrm{pm}$. The measurements were taken during the med. month of august 2018. The latitude and longitude of the location were $30.053934 \mathrm{~N}, 31.320564$ E. A primary measurement on the field were to carry out the forward speed by using speed box controlled with electric adapters of 12,16 , 20 and 24 volts at a distance of $15 \mathrm{~m}$ and the time was determined by stopwatch. The average forward speed is $0.27,0.55,0.85$ and $1.12 \mathrm{~m} / \mathrm{s}$ by four electric adapters of $12,16,20$ and 24 volts respectively. To element the effect of response time to ensure that the spray process starting and ending of the beginning and ending of target tree respectively, the webcam must be located ahead of spray nozzle at a distance depending on the spraying speed which defined as webcam leading distance. For measuring a response time of the prototype electronic components, a brunch of experiments orange tree was used. The time between putting the tree branch and starting the spray was measured by a digital stopwatch $( \pm 0.01 \mathrm{~s})$ and defined as start time. The experiment was repeated seven time by four different persons to eliminate the human response time. As the time between removed the tree brunch and ending spray was measured and defined as end time. The webcam leading distance (d) was estimated by the following equation: $\quad d=\mathrm{S} \times \mathrm{Rt}$

Where, $\mathrm{S}$ : is the forward speed, $(\mathrm{m} / \mathrm{s})$, and Rt: is the response time, (s).

A sheet of white papers were located before and after target tree at a vertical distance equal to the prototype nozzle. The prototype was operated at four forward speeds of $0.27,0.55,0.85$ and 1.12 $\mathrm{m} / \mathrm{s}$ by using a colored liquid and the distance between starting and ending spraying was measured from the white papers by measuring tape. A new white paper was used for each experiment. Each experiment was repeated three times and the average was calculated. Each nozzle was installed in the experimental prototype and the sprayer was operated at four different spraying pressure of 250 , 300,350 and $400 \mathrm{kPa}$ using the pressure regulator. The field experiment was carried out using RGB code for webcam distance of $1 \mathrm{~m}$ and daytime from 5.00 to $10.00 \mathrm{am}$ and from 3.00 to $6.00 \mathrm{pm}$. A prototype tank was filled with spraying liquid and operated for $21 \mathrm{~m}$ distance of which have five orange trees. The experiments were carried out under the following variables: Prototype forward speeds $(0.27,0.55,0.85$ and $1.12 \mathrm{~m} / \mathrm{s})$, Spray pressures $(250,300,350$ and $400 \mathrm{kPa})$ and Nozzle types $\left(\mathrm{N}_{1}, \mathrm{~N}_{2}, \mathrm{~N}_{3}\right.$ and $\left.\mathrm{N}_{4}\right)$. After each experiments a prototype tank was refilled usin'g a graduated flask and the amount of spraying was recorded. The experiment was done with/without vision. In order to avoid the effect of using one spraying nozzle, the percentage of amount liquid reducing "qs" was measured by the following equation.

$$
q_{s}=\frac{q_{\text {without }}-q_{\text {with }}}{q_{\text {without }}} \times 100
$$

Where: $q_{\text {without: }}$ amount of spraying liquid without vision technique; and $\mathrm{q}_{\text {with }} \quad$ : amount of spraying liquid with vision technique. 
For the prementioned experiments a spraying intensity was measured using rain intensity device $( \pm$ $0.01 \mathrm{~mm}$ ). The three sensors of the rain intensity device were located at the beginning, middling and ending of the third experimented tree.

\section{RESULTS AND DISCUSSION}

\section{Laboratory experiments}

\section{Image analyses}

Figure (3) illustrate the sun light intensity "£" (lx) at different daily hours "T" (h). It was observed that the sun light intensity increases with the increase of daily hours until $12.00 \mathrm{pm}$, then decreases with the increase of daily hours from 3.00 to $6.00 \mathrm{pm}$. This behavior logically expected for the data of experimental, which mean that the daily hours of $12 \mathrm{pm}$ represent reversal point. The values of light intensity were used to identify its effect on RGB values. Therefore, the daily hours was replaced by the corresponding values of light intensity.

Figure (4) illustrated the values of the low and high of RGB colors for images and daily hours as affected by the daily hours "T" (h) at different webcam/tree distances "D" (m). It was observed from figures 3 and 4 that the low and high RGB values increases with the increase of morning daily hours from 5.00 to 10.00 am for all color while afternoon, there were decreases with the increase of daily hours from 3.00 to $6.00 \mathrm{pm}$. These results were corresponding to the sun light intensity.

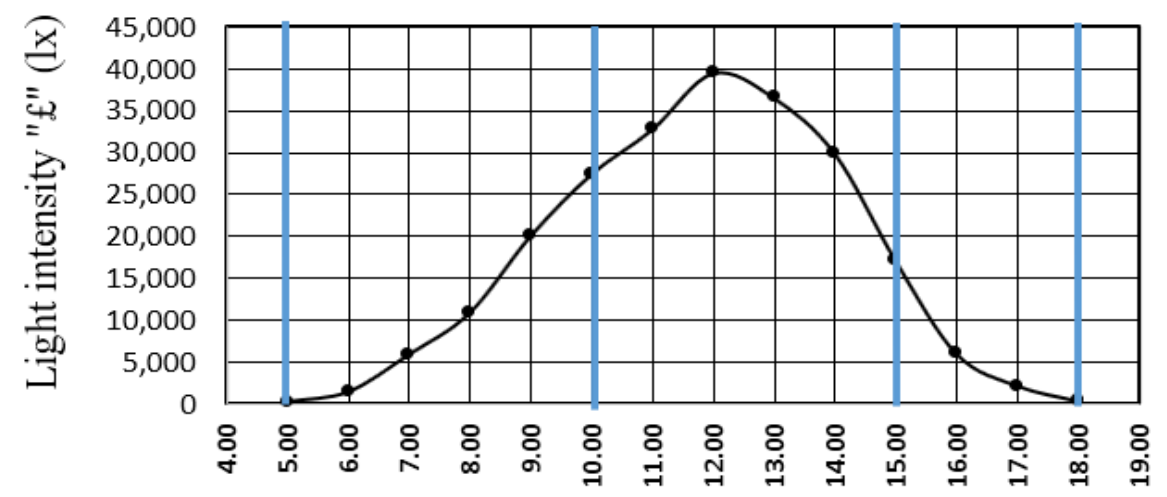

Daily hours "T" (h)

Fig. (3): light intensity "£" (lx) at different daily hours "T" (h).(mid. of august 2018, 30.053934 N, 31.320564 E).

The figures illustrated also that there are slightly different between the values of RGB colors for low values while the difference was higher for high values especially at $1 \mathrm{~m}$ of webcam/tree distance "D" (m). In order to have a wide RGB code to cover all operating daily hours, the low values of RGB was obtained at 5.00 am while the high values of RGB was obtained at 9.00 am for the morning daily hours. The values of low and high were 32, 49, 35 and 205, 255 and 209 respectively. The low values of RGB was obtained at $6.00 \mathrm{pm}$ while the high values of RGB was obtained at $3.00 \mathrm{pm}$ for the evening daily hours. The values of low and high were 39, 55, 33 and 186, 223, 167 respectively per one meter of webcam/tree distance "D" (m). 
Low values of RGB

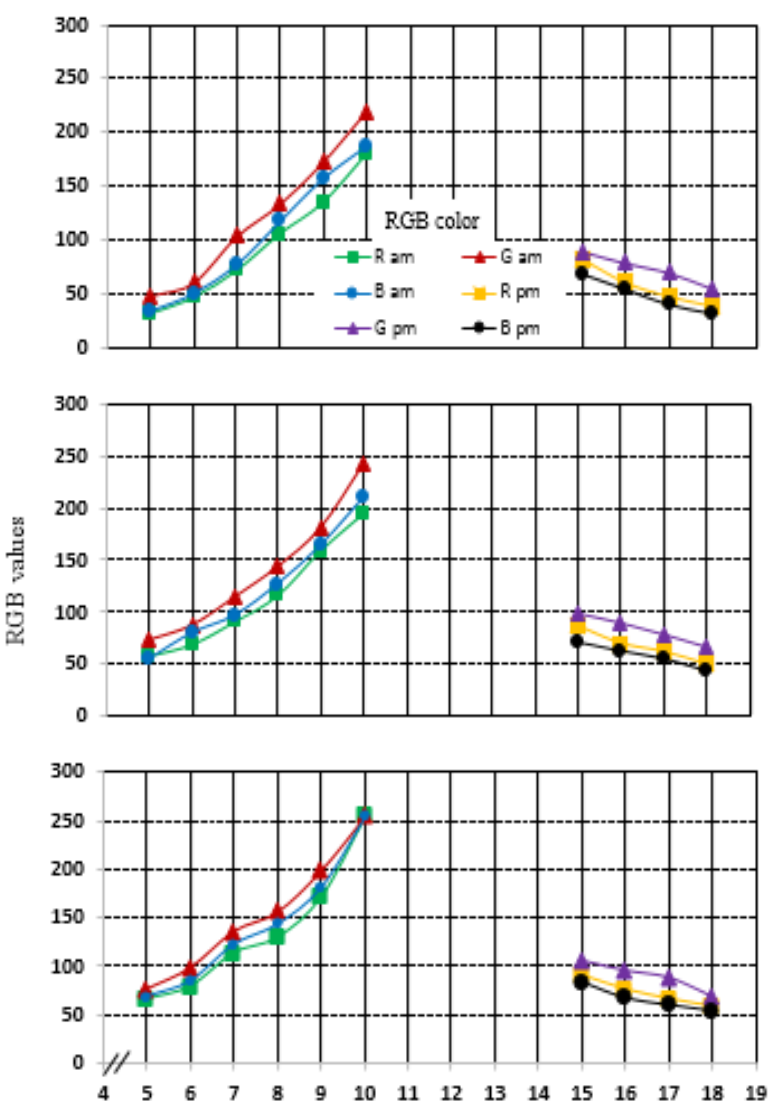

High values of RGB
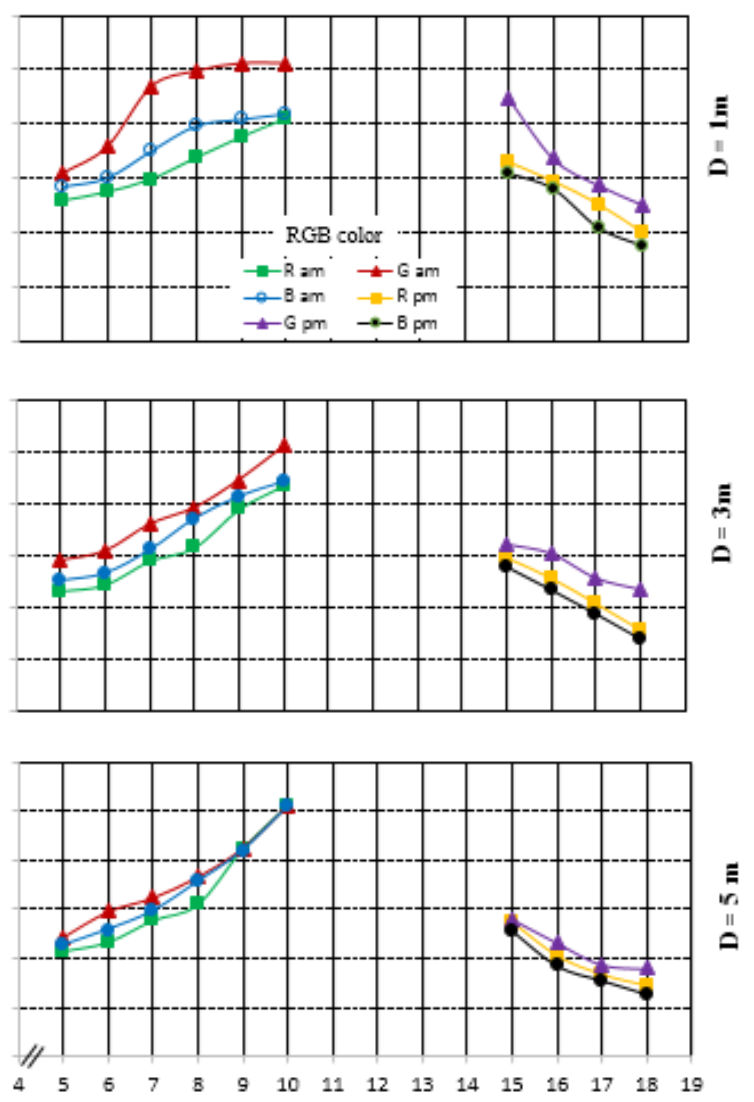

Daily hours, $h$

Fig. (4): Low and high values of RGB at different daily hours "T" (h) and webcam/tree distance "D" (m).

The analysis of variance for RGB values (LRGB and HRGB respectively) as a dependent variable (LSD value was calculated by using ANOVA at levels of 0.05 and 0.01 ) indicated that the distance between webcam and target tree and daily hours have a high significant effect on low and high RGB values.

\section{Prototype electronic circuit response time}

Table 3 shows the start and end times of spray process of four individual persons with seven replicates.

The results showed that the average of starting time was $3.00 \mathrm{~s}$ and the average of ending time was $3.52 \mathrm{~s}$ with a difference of $0.52 \mathrm{~s}$ and the average response time is $3.26 \mathrm{~s}$. Table 4 show the webcam leading distances at different spray forward speed according to the equation 3.1 for the three prementioned response times. 
Table 3: Mean response time for electronic circuit

\begin{tabular}{|c|c|c|c|}
\hline Person No. & $\begin{array}{l}\text { start and end times of } \\
\text { spray process }(\mathrm{s})\end{array}$ & Mean, s & CV \% \\
\hline 1 & \multirow{4}{*}{ Start time } & 2.96 & 3.60 \\
\hline 2 & & 3.03 & 4.97 \\
\hline 3 & & 3.01 & 3.16 \\
\hline 4 & & 3.01 & 2.55 \\
\hline & & 3.00 & 3.58 \\
\hline 1 & \multirow{4}{*}{ End time } & 3.56 & 4.11 \\
\hline 2 & & 3.52 & 4.25 \\
\hline 3 & & 3.54 & 4.16 \\
\hline 4 & & 3.51 & 4.80 \\
\hline & & 3.52 & 4.68 \\
\hline
\end{tabular}

Table 4: Webcam leading distance " $L "$ (m) at different spray forward speeds " $S$ " ( $\mathrm{m} / \mathrm{s})$ and response time " $R$ " (s)

\begin{tabular}{cccc}
\hline \multirow{2}{*}{$\begin{array}{c}\text { Spray forward speed } \\
\text { "S" (m/s) }\end{array}$} & \multicolumn{3}{c}{ Webcam leading distance "L" (m) } \\
\cline { 2 - 4 } & 3.00 & 3.26 & 3.52 \\
\hline 0.27 & 0.81 & 0.88 & 0.95 \\
0.55 & 1.65 & 1.79 & 1.94 \\
0.85 & 2.51 & 2.77 & 2.99 \\
1.12 & 3.36 & 3.65 & 3.94 \\
\hline
\end{tabular}

Figure (5) illustrated the intervals spraying distance before/after target trees "d" (m) as affected by the spraying forward speed "S" (m/s) and webcam leading distance "L" (m). It was observed that the spray distance before/after the tree increased with the increased of spray forward speed for the three investigated response time.

This result lead to a small difference for the coverage at distances before/after target treat low speed, and lead to a great difference at high speed. While the average response time of $3.26 \mathrm{~s}$ gave almost equal difference at spraying forward speeds. The spray distances at response time of $3.26 \mathrm{~s}$ before/after target tree at forward speed of $0.27 \mathrm{~m} / \mathrm{s}$ were 8.3 and $6.2 \mathrm{~cm}$ respectively which represent $9.5 \%$ losses of spraying liquid. While at spray forward speed of $1.12 \mathrm{~m} / \mathrm{s}$ were 25.7 and $23.0 \mathrm{~cm}$ respectively which represent of $32.5 \%$ losses of spraying liquid. The spray liquid losses couldn't be avoided in order to ensure the complete coverage of the target tree was done but could be eliminated by using low spraying forward speed. Therefore, the average response time of $3.26 \mathrm{~s}$ was used for the next field experiments. Fig. (6) illustrate the effect of spraying pressure on discharge at different nozzle types. The results indicated that increasing of pressure increased the discharge for all different nozzle type. Nozzles $\left(\mathrm{N}_{1}\right.$ and $\left.\mathrm{N}_{2}\right)$ given the smallest discharge at different pressures, whole, nozzles $\left(\mathrm{N}_{3}\right.$ and $\left.\mathrm{N}_{4}\right)$ given the highest flow rate compering with the other nozzle types. The discharge was 1.10,1.40,1.80 and $2.22 \mathrm{~L} / \mathrm{min}$ at $250,300,350$ and $400 \mathrm{kPa}$ pressure respectively for nozzle $\mathrm{N}_{4}$. 


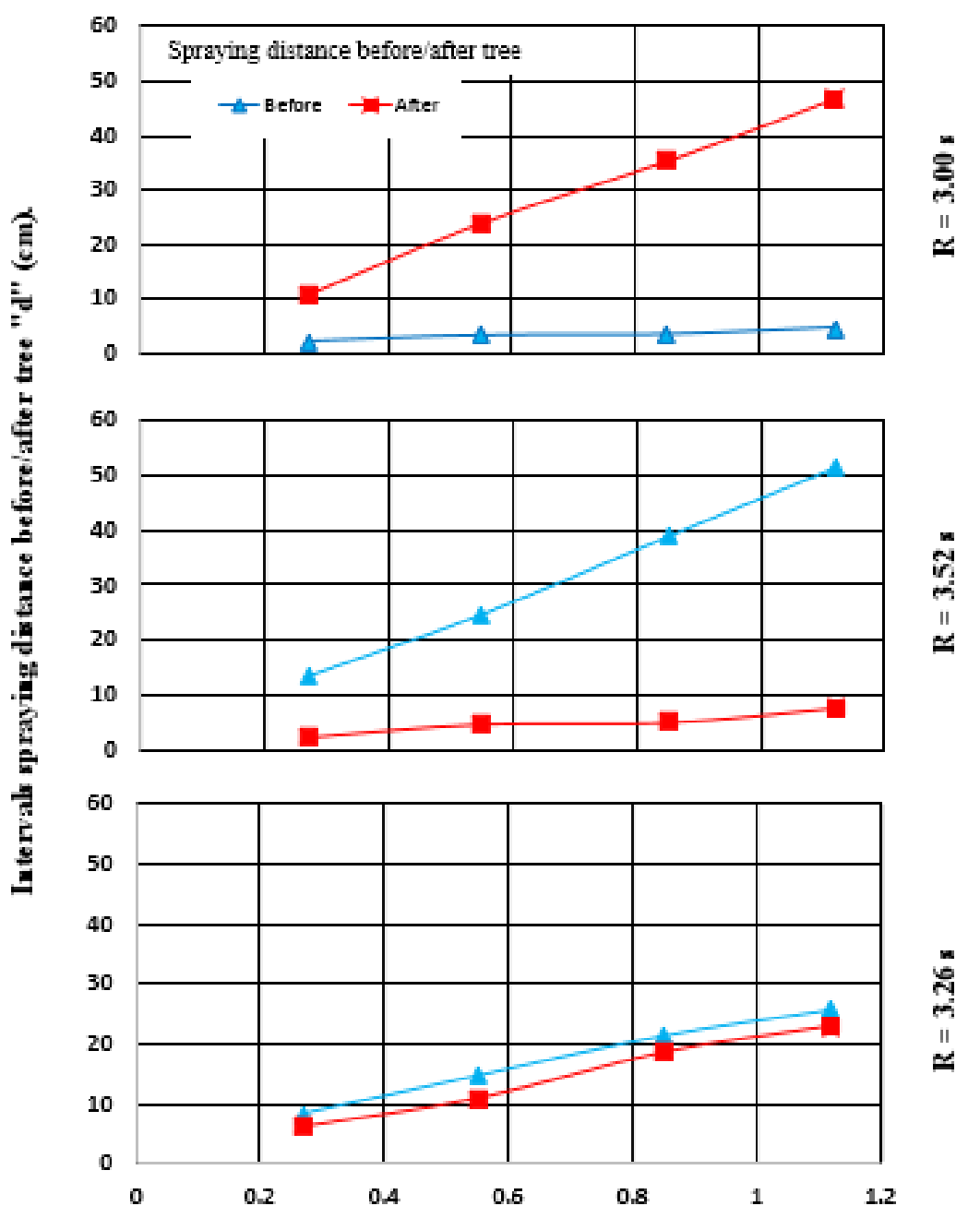

Spraying forward speed "S" (m/s)

Fig. (5): Spraying distance before/after tree "d" (m) Vs. spraying forward speed "S" (m/s) at different response time " $R$ " (s) (tree width of $150 \mathrm{~cm}$ ).

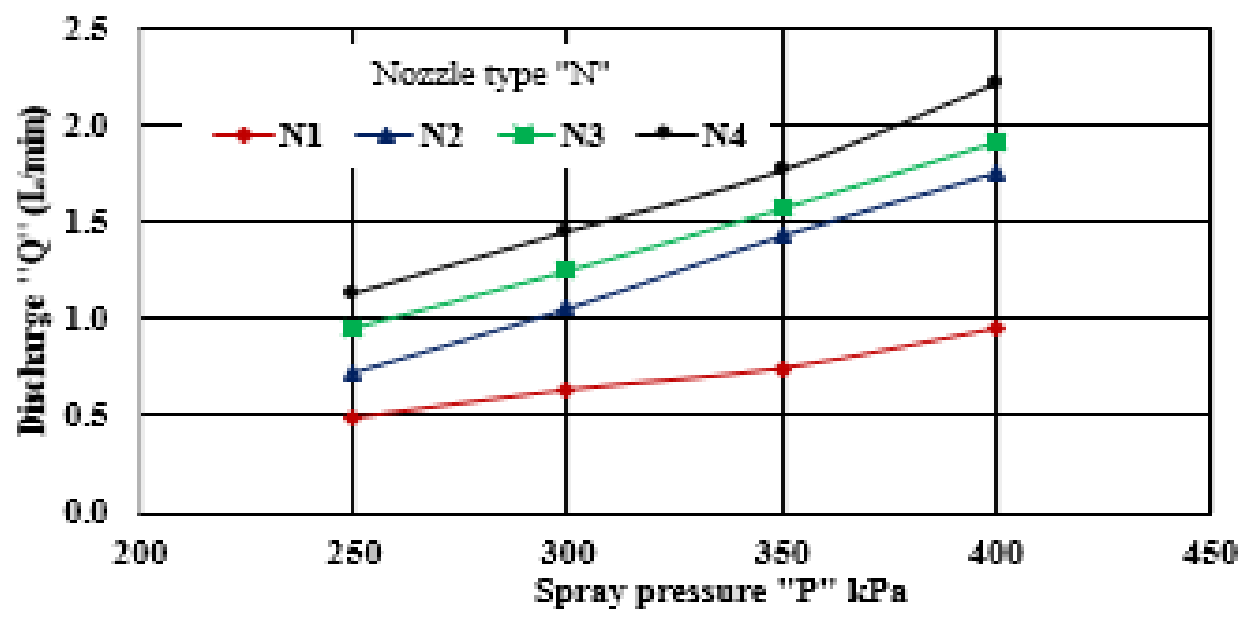

Fig. (6): Discharge " $Q$ " (L/min) VS. spraying pressure "P"

$(\mathrm{kPa})$ at different nozzle types " $\mathrm{N}$ ". 


\section{Field experiments.}

Figure (7) illustrated the amount of consumed pesticide with/without vision technique "q" (L/tree) as affected by the spraying forward speed "S" (m/s), nozzle types "N" and spraying pressure "P" (kPa). It was observed that the amount of consumed pesticide decreased with the increase of spray forward speed and increased with the increase the spray pressure for all nozzle type during with/without vision technique. Without vision technique, the maximum value of spray liquid consumption was $3.794 \mathrm{~L} /$ tree at nozzle type $\mathrm{N}_{4}$, spray pressure of $400 \mathrm{kPa}$ and spray forward speed of $0.27 \mathrm{~m} / \mathrm{s}$. while, the minimum value of spray liquid consumption was $0.212 \mathrm{~L} /$ tree at nozzle type $\mathrm{N}_{1}$, spray pressure of $250 \mathrm{kPa}$ and spray forward speed of $1.12 \mathrm{~m} / \mathrm{s}$. While for vision technique the maximum value of the spray liquid consumption was 1.610 L/tree with nozzle type $\mathrm{N}_{4}$, spray pressure of $400 \mathrm{kPa}$ and forward speed of $0.27 \mathrm{~m} / \mathrm{s}$. while, the minimum value of the spray liquid consumption was $0.110 \mathrm{~L} /$ tree with nozzle type $\mathrm{N}_{1}$, pressure $250 \mathrm{kPa}$ and spray forward speed of $1.12 \mathrm{~m} / \mathrm{s}$. It will be noticed that the vision technique leads to saving a spray liquid for all the experimental variable.

The analysis of variance for the amount of spray liquid consumption by using vision technique and without "q" (L) as a dependent variable (LSD value was calculated by using ANOVA at levels of 0.05 and 0.01 ) indicated that the spray forward speed "S", nozzle type "N" and spray pressure "P" have a high significant effect on the amount of spray liquid consumption by using vision technique and without.

Figure (8) illustrated the percentage of amount spray liquid saving due to vision technique as affected by the spraying forward speed "S" (m/s), nozzle types " $\mathrm{N}$ " and spraying pressure "P" $(\mathrm{kPa})$. The result showed that the percentage of amount spray liquid saving decreased with the increases of spraying forward speed and increased with the increases spraying pressure. The maximum percentage amount of saving spray liquid was $57.57 \%$ at nozzle type $\mathrm{N}_{4}$, spraying pressure of $400 \mathrm{kPa}$ and spraying forward speed of $0.27 \mathrm{~m} / \mathrm{s}$ by using vision technique than without. While, the minimum percentage of amount spray liquid saving was $47.82 \%$ at nozzle type $\mathrm{N}_{1}$, spray pressure of $250 \mathrm{kPa}$ and spraying forward speed of $1.12 \mathrm{~m} / \mathrm{s}$ using vision technique than without. The optimum percentage of amount spray liquid saving was $57.57 \%$ at nozzle type $\mathrm{N}_{4}$, spraying pressure of $400 \mathrm{kPa}$ and spraying forward speed of $0.27 \mathrm{~m} / \mathrm{s}$ using vision technique than without.

The analysis of variance for the percentage of amount spray liquid saving (\%) as a dependent variable (LSD value was calculated by using ANOVA at levels of 0.05 and 0.01 ) indicated that the spraying pressure "P" and nozzle type "N" have a high significant effect of the amount of spray liquid consumption by using vision technique and without "q", but it was non-significant effect for spraying forward speed on the percentage of amount spray liquid saving.

Figure (9) recorded the spraying intensity "I" (mm) at beginning, middling and ending sensor located on tree as affected by the spray forward speed "S" $(\mathrm{m} / \mathrm{s})$, nozzle type $(\mathrm{N})$ and spray pressure "P" $(\mathrm{kPa})$. It was observed that the spraying intensity at beginning, middling and ending sensors located on trees increased with the increases of spraying pressure for all spraying forward speeds and nozzle type. The figures indicated also that there are slightly different 
between the spraying intensity at first and last target tree while the difference was higher for spraying intensity at middling tree especially at spray pressure of $250 \mathrm{kPa}$ and nozzle type $\mathrm{N}_{1}$.

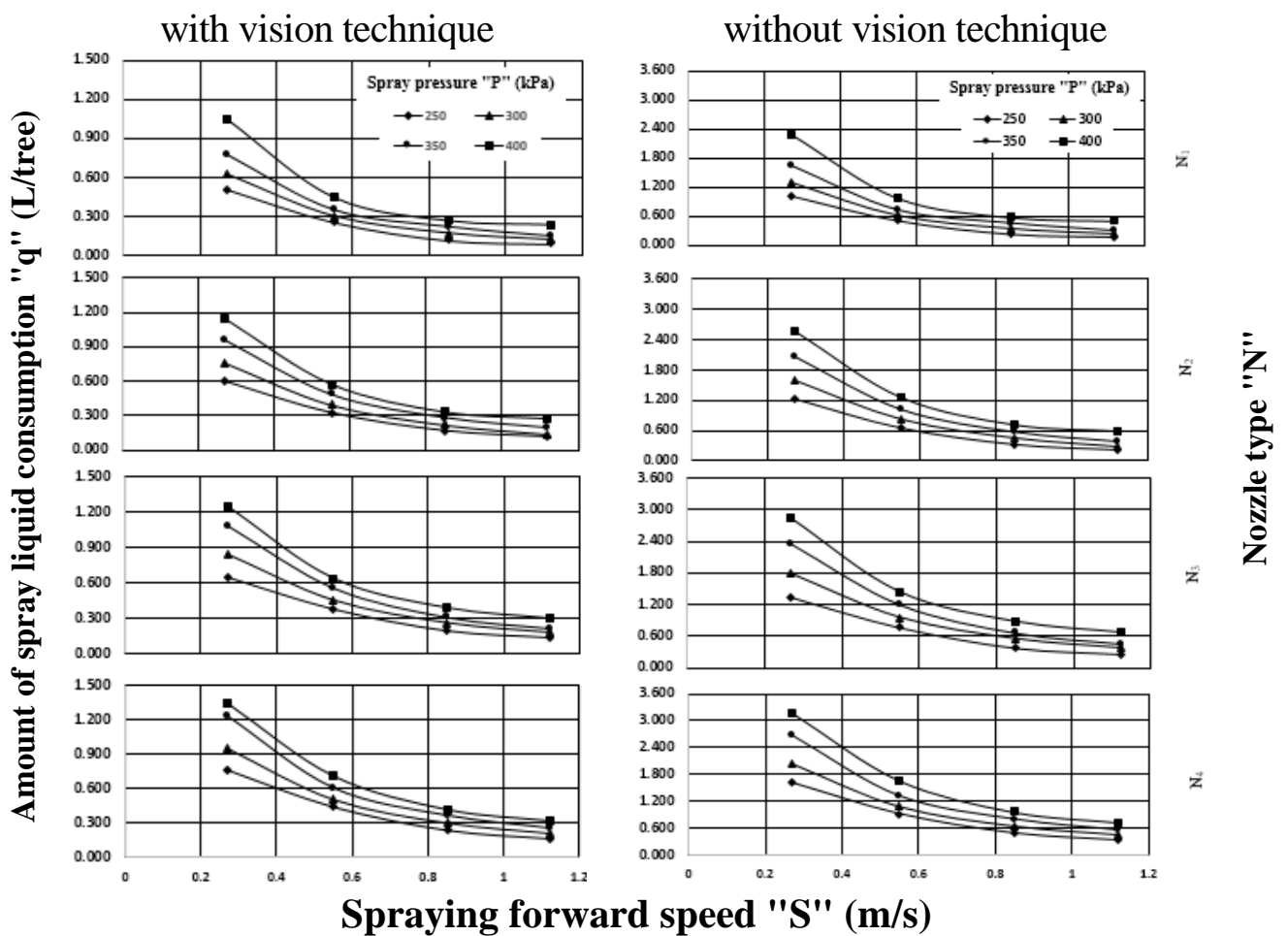

Fig. (7): Amount of spray liquid consumption "q" (L/tree) Vs. spraying forward speed "S" (m/s) at different nozzle types $(\mathrm{N})$ and spray pressure "P" (kPa) with and without vision technique.
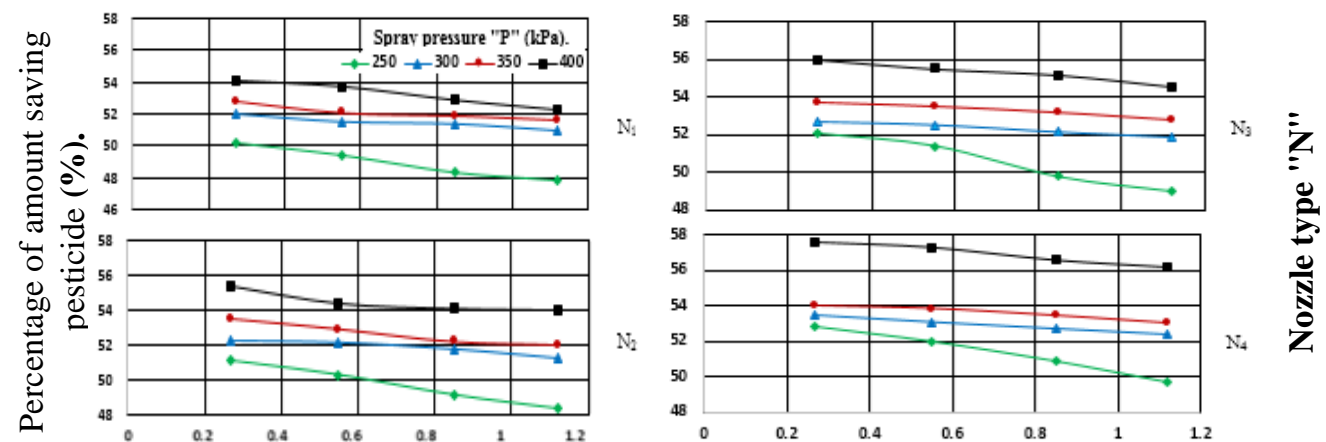

Spraying forward speed " $\mathrm{S}$ " $(\mathrm{m} / \mathrm{s})$

Fig. (8): Amount of spray liquid consumption "q" (L/tree) Vs. spraying forward speed "S" (m/s) at different nozzle types $(\mathrm{N})$ and spray pressure "P" ( $\mathrm{kPa})$ with and without vision technique. 


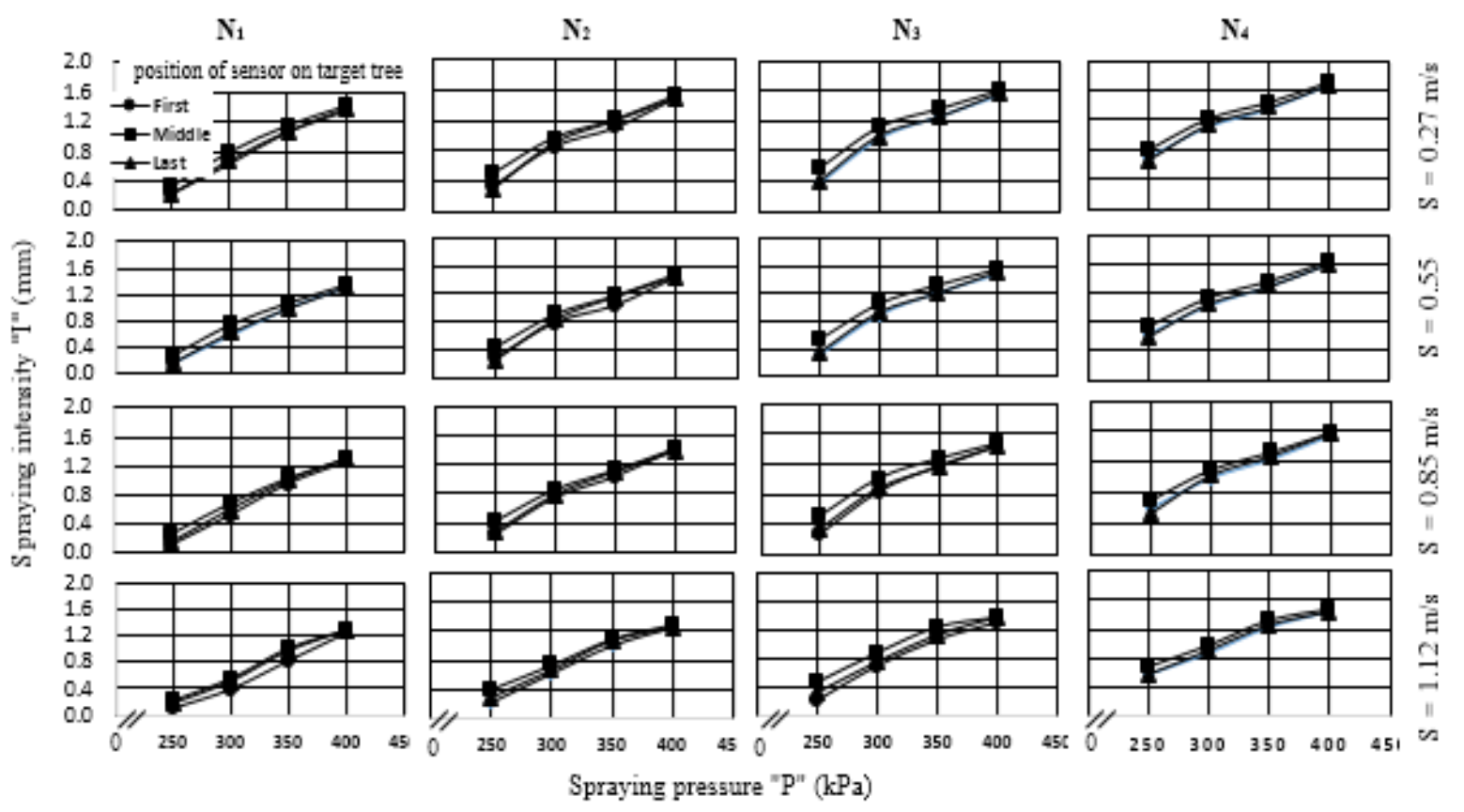

Fig. (9): Spraying intensity "I" (mm) Vs. spraying pressure "P" (kPa) at beginning, middling and ending sensors located on target tree, different nozzle type "N" and spraying forward speed "S" (m/s).

The analysis of variance for the spray intensity "I" as a dependent variable (LSD value was calculated by using ANOVA at levels of 0.05 and 0.01 ) indicated that the forward speed "S", nozzle type "N" and spraying pressure "P" have a high significant effect on spray intensity for first, middle and last sensors located at tree "I".

\section{CONCLUSION}

1. It was observed that the RGB values increased with the increase light intensity for Anti meridian daily hours (am) while slightly increases with the increase of light intensity for post meridian daily hours ( $\mathrm{pm})$. Also, that there are slightly different between the values of RGB colors for low values while the difference was higher for high values especially in $1 \mathrm{~m}$ of webcam distance.

2. the spray distance before and after the tree increased with the increased of spray forward speed for the three investigated response time.

3. the amount of consumed pesticide decreased with the increase of spray forward speed and increased with the increase the spray pressure for all nozzle type, with and without vision technique. Also, that the vision technique leads to saving a spray liquid for all the experimental variable.

4. the percentage amount of saving spray liquid decreased with the increase of spray forward speed and increased with the increase the spray pressure.

5. the spray intensity at first, middle and last trees increased with the increased of spray pressure for all forward speeds and nozzle type. 


\section{REFERENCES}

Brosnan, T., \& Sun, D. W. (2004). Improving quality inspection of food products by computer vision - a review. Journal of food engineering, 61(1), 3-16.

Brown, D. L., Giles, D. K., Oliver, M. N., \& Klassen, P. (2008). Targeted spray technology to reduce pesticide in runoff from dormant orchards. Crop Protection, 27(3-5), 545552.

FAO (Food and Agricultural Organization) (2016). Pesticides Use http://www.fao.org/faostat/en/\#data/RP.

Ismail A. M., H. Rashad, Z. Imara and A. E. Rezk. (2015) development of an autonomous navigation agricultural robotic platform based on machine vision. Misr J. Ag. Eng., 32 (4): $1421-1450$.

Merritt, S. J., G. E. Meyer, K. Von Bargen, and D. A. Mortensen. (1994). Reflectance sensor and control system for spot spraying. ASAE Paper No. 941057. St. Joseph, Mich.: ASAE.

Oerke, E. C. (2006). Crop losses to pests. The Journal of Agricultural Science, 144(1): 31-43.

https://www.google.com/url?sa=t\&rct=j\&q=\&esrc=s\& source=web\&cd=2\&cad=rja\&uact=8\&ved=2ahUKEwjng 7Si1sHeAhUJDOwKHS0xCmwQFjABegQIAxAC\&url=http\%3A\%2F\%2Fciteseerx.ist.psu.edu\%2Fv iewdoc\%2Fdownload\%3Fdoi\%3D10.1.1.657.5813\%26rep\%3Drep1\%26type\%3Dpdf\&usg=AOvVaw 38tFZ9 wAcNUlF7jdvdEOcO

Padmavathi, K., and K. Thangadurai (2016). Implementation of RGB and grayscale images in plant leaves disease detection-comparative study. Indian Journal of Science and Technology, 9(6). 


\section{نموذج أولى لرش المبيدات باستخذام تقنية الروئية}

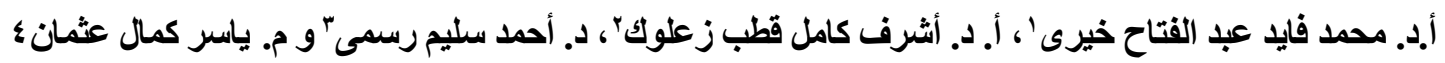

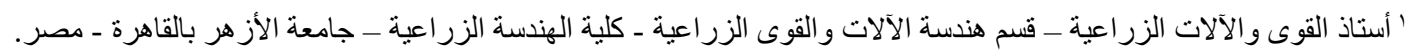

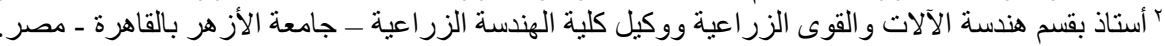

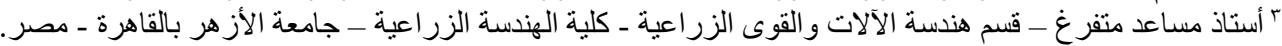

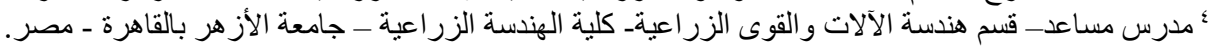

\section{الملخـص العـربى}

تستخدم آلات الرش التقليدية في رش المحاصيل البستانية لكامل وحدة المساحة بما في

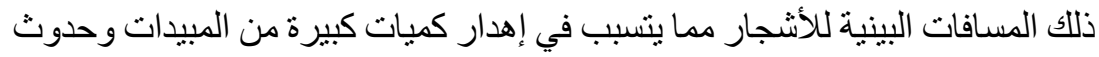

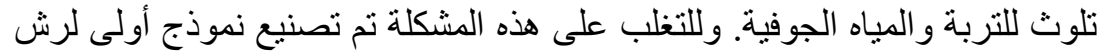

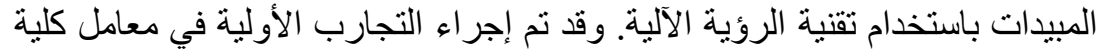

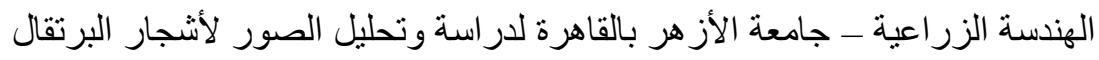

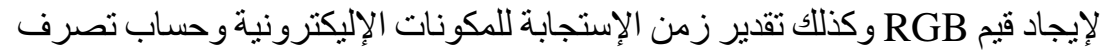

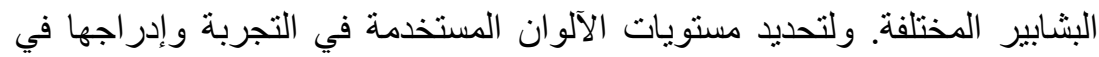

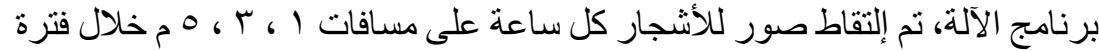

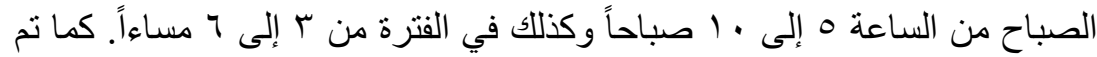

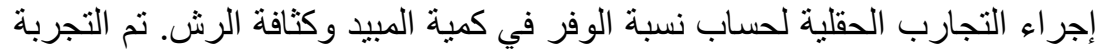

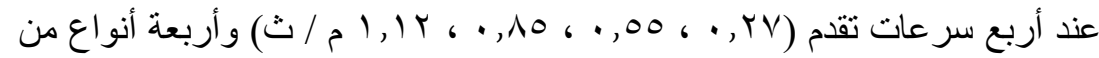

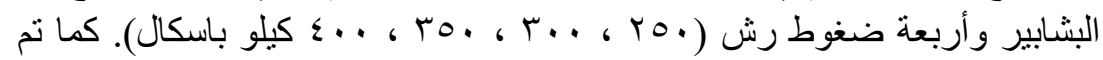

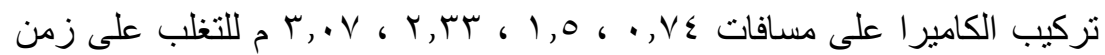

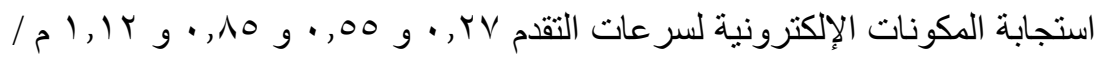

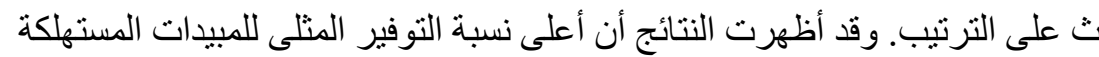

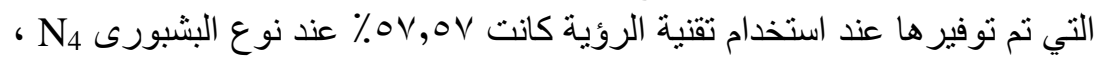

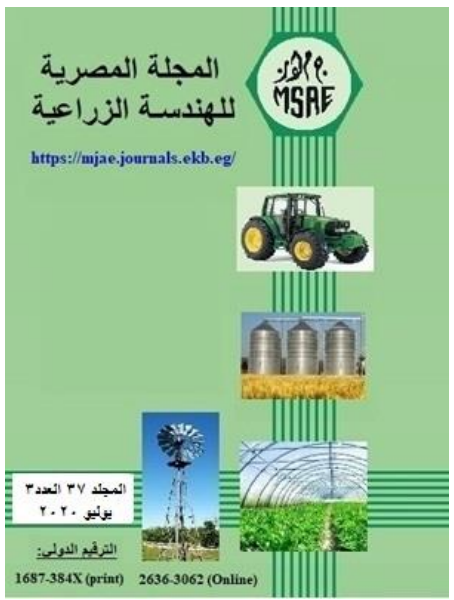

(C) (المجلة المصرية للهندة الزراعية

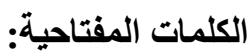
تقنية الرؤية الآلية، رش المبية، المبيدات،

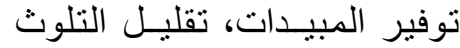

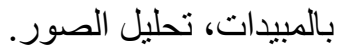

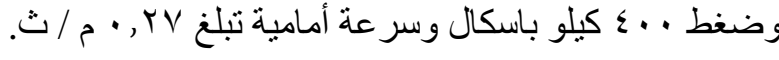

